\title{
Low Molecular Weight Heparin in Atrial Fibrillation Management: Facts, Fiction, Future
}

\author{
Michael H. Kim, ${ }^{1}$ Richard G. Trohman ${ }^{1}$ \\ and Kim A. Eagle ${ }^{2}$ \\ ${ }^{1}$ Section of Cardiology, Rush-Presbyterian-St. Luke's Medical \\ Center, Chicago, IL; ${ }^{2}$ Division of Cardiology, University of \\ Michigan Medical Center, Ann Arbor, MI
}

\begin{abstract}
Background: Atrial fibrillation (AF) is the most common sustained arrhythmia and various AF disease management strategies can be utilized.

Methods: A prospective, randomized pilot study of two AF disease management strategies was conducted at a single university hospital in patients newly diagnosed with AF. The impact of low molecular weight heparin (LMWH) on AF management strategies is discussed with respect to the current guidelines for AF management, existing data on LMWH for AF, and recent investigations pertaining to $\mathrm{AF}$.

Results: 18 patients were enrolled. The accelerated emergency department based strategy utilizing LMWH resulted in a significant reduction in length of stay (2.1 \pm 2.3 versus $<1$ day) and a trend toward lower costs $(\$ 1,706 \pm 1,512$ versus $\$ 879 \pm 394 ; p=0.15)$ when compared to the more traditional strategy of hospital admission. Measured clinical outcomes were similar for both treatment strategies.

Conclusions: The investigation showed that an outpatient, emergency department based disease management strategy for new, uncomplicated AF could result in clinically acceptable, cost-effective innovations in AF treatment strategies. LMWH is an example of an agent allowing innovations in disease management strategies.
\end{abstract}

Key Words. low molecular weight heparin, atrial fibrillation, anticoagulants

\section{Introduction}

Atrial fibrillation (AF) is the most common sustained arrhythmia and will become more prevalent with the aging of the population [1]. The management strategy for this condition on both an individual clinician and health system organization level at the time of initial hospital presentation is controversial and there is wide practice variation. Because of the association of $\mathrm{AF}$ with cardiovascular complications and stroke, the choice of management strategy could have a profound impact on the economics of AF disease management.

A prospective, randomized pilot study of two AF disease management strategies was conducted at a single university hospital in low-risk individuals with newly diagnosed or new-onset AF [2]. This investigation compared a traditional strategy of hospital admission versus an accelerated emergency department based clinical pathway that utilized a low molecular weight heparin (LMWH), dalteparin, and early cardioversion to sinus rhythm. Transesophageal echocardiography was used prior to cardioversion in selected patients in accordance with clinical guidelines [3]. The study population consisted of 18 patients randomized over a 15 month period who presented to the emergency department with uncomplicated newly diagnosed or new-onset $\mathrm{AF}$ who had no indication for hospital admission other than AF and were candidates for anticoagulation. The primary endpoints were length of stay and total actual direct costs.

The accelerated emergency department based strategy was associated with a significant reduction in length of stay ( $2.1 \pm 2.3$ versus $<1$ day) and a trend toward lower costs $(\$ 1,706 \pm \$ 1,512$ versus $\$ 879 \pm$ $\$ 394 ; p=0.15$ ). Measured clinical outcomes (rate of sinus rhythm at discharge and one month follow-up and AF-related complications) were similar for both treatment strategies. Dalteparin was used to facilitate early treatment and discharge in all the accelerated emergency department strategy patients. The mean number of dalteparin doses was $6.2 \pm 4.3$, which was nearly $40 \%$ of the total actual direct cost for this strategy. More direct current cardioversion procedures were performed with the emergency department based strategy due to less time allowed for spontaneous AF conversion.

In summary, the investigation [2] showed that an outpatient, emergency department based diseasemanagement strategy for new, uncomplicated AF could result in clinically acceptable, cost-effective innovations in AF treatment strategies. LMWH is an example of an agent allowing innovations in disease management strategies.

\section{Data on LMWH for AF: "Fact and Fiction"}

The data are clear that warfarin anticoagulation reduces the risk of stroke in patients with $\mathrm{AF}$ who have

Address correspondence to: Michael H. Kim, M.D., RushPresbyterian-St. Luke's Medical Center, 1653 W. Congress Parkway, Chicago, IL 60612. E-mail: Michael_Kim@rush.edu 
risk factors for thromboembolism and that warfarin therapy is superior to aspirin in high-risk individuals [3-5]. Nevertheless, prophylactic warfarin for the prevention of thromboembolism and stroke in AF patients is grossly underutilized in clinical practice for a variety of reasons [5]. Given the practical limitations of warfarin therapy, novel anticoagulants such as oral direct thrombin inhibitors, antiplatelet combinations, and left atrial appendage occlusion devices are under investigation or development [5]. The role of LMWH in AF has followed an analogous course to these potential replacements for traditional anticoagulants like heparin and warfarin, especially in the areas of disease management in the inpatient setting and peri-cardioversion facilitation.

Unfractionated heparin and warfarin have been the mainstays of anticoagulant therapy for many years. These agents are commonly used in the initial stages of anticoagulation for short-term medical management and subsequently the long-term prevention of thromboembolism. However, in recent years data on the use of LMWH for the treatment of venous thromboembolism and acute coronary syndromes have demonstrated it's clinical efficacy and ease of use [6]. LMWH is increasingly being used as a protective anticoagulant for AF, mainly to replace unfractionated heparin, perhaps in part to decrease the hospital length of stay $[7,8]$. This practice pattern of LMWH use in AF exists despite minimal data as to the efficacy or safety of this strategy.

Early reports of LMWH use in AF noted the benefit of LMWH for thromboprophylaxis in comparison to no specific therapy [9] and in patients intolerant of warfarin [10]. More recent studies have shown that LMWH (dalteparin) could be successfully used to minimize stroke risk during cardioversion of $\mathrm{AF}$ in patients without previous anticoagulation who have no thrombus on transesophageal echocardiography [11]. Other preliminary reports noted the potential cost-effectiveness of using LMWH (dalteparin) in outpatient AF management when compared to more traditional admission for intravenous heparin until therapeutic levels of warfarin are achieved [12] and the non-inferiority and safety of LMWH (enoxaparin) in the process of $\mathrm{AF}$ cardioversion, predominantly via a transesophageal echocardiography guided approach [13].

The conventional approach $[3,14]$ to the cardioversion of AF with warfarin is based on nonrandomized studies that showed fewer complications in warfarin treated patients. Despite the limitations of such data, this conventional anticoagulant approach is widely accepted due to historical safety data available back to the 1960's [15,16]. The conventional approach has also compared favorably to the transesophageal echocardiography guided strategy with an essentially equivalent stroke risk with cardioversion regardless of chosen AF cardioversion strategy [17].
Both the conventional and transesophageal echocardiography guided strategy for cardioversion of $\mathrm{AF}$ are accepted standards. The use of LMWH rather than unfractionated heparin as a bridge to warfarin anticoagulation for cardioversion of AF remains unsettled. Clearly, there may be benefits to LMWH from a cost perspective if the transesophageal echocardiography guided approach is chosen [18] and a reduction in admission rates by allowing outpatient based AF management for low-risk individuals. Much needed clarification of the role of LMWH in transesophageal echocardiography guided cardioversion will come from the Assessment of Cardioversion Using Transesophageal Echocardiography (ACUTE) II Study [19] and the Anticoagulation in Cardioversion using Enoxaparin (ACE) Study [20], both of which will be comparing LMWH versus intravenous heparin strategies.

\section{LMWH for AF: "Future"}

LMWH and novel anticoagulants, in general, will continue to impact and alter AF disease management strategies. The AFFIRM Trial [21] showed that a strategy of rate control and rhythm control in the presence of warfarin anticoagulation are both reasonable strategies in AF. Nevertheless, cardioversion of AF will continue to be an important clinical entity due to symptomatic AF and potential patient preference for sinus or "normal" rhythm. Furthermore, the data from AFFIRM cannot necessarily be extrapolated to younger AF patients or certain subsets of $\mathrm{AF}$, such as new-onset or newly diagnosed AF. It is not entirely clear that the risk of stroke can be reduced by restoring sinus rhythm [21,22], but data from the AFFIRM stroke substudy suggest that the continued presence of AF increases stroke risk and the use of warfarin reduces such risk regardless of AF management strategy [23].

The use of LMWH for cardioversion of AF should expedite cardioversion similar to intravenous heparin with the possible added benefit of avoiding hospital admission and reducing costs in a significant number of patients. Outpatient management of AF will become more common as more data show that certain subgroups of AF patients can be safely managed without hospitalization [2,24-26]. There may also be an increased likelihood of maintaining sinus rhythm with earlier cardioversion, although data conflict $[11,17,27]$. Although warfarin without any form of heparin can be used in patients not requiring admission, the time required to actually satisfy the current anticoagulation recommendations [3,14] prior to cardioversion is often longer than 3 to 4 weeks due to the time required to reach the initial therapeutic INR and the frequency of subtherapeutic INR values following the initial therapeutic value [28]. This prolonged time to cardioversion should be 
considered when formulating disease management based approaches to AF.

In summary, there is a promising future for LMWH in AF disease management for both low and high risk patients. LMWH has a favorable pharmocologic profile, is easy to use, requires little to no monitoring, has potential economic benefits, and has broad flexibility in clinical (inpatient/outpatient) applications. Clearly, the use of LMWH for AF is expanding for these reasons despite the paucity of data from controlled clinical trials. We suspect that this trend will continue, but hopefully in tandem with more investigational data. Nevertheless, at the current time, caution should be exercised in the use of LMWH for AF since minimal data on efficacy and safety exist. Furthermore, it is not clear that all "LMWH" are equal from a therapeutic standpoint [29]. Future novel anticoagulants will allow innovative and perhaps more cost-effective AF management strategies. Most promising, other than the LMWH, are the oral direct thrombin inhibitors, such as Ximelagatran, a potential LMWH and warfarin substitute [5]. In addition to the stroke prevention trials of Ximelagatran, additional safety and efficacy data for cardioversion of AF will be needed to fully integrate such a new agent into $\mathrm{AF}$ disease management strategies.

\section{References}

1. Go AS, Hylek EM, Phillips KA, Chang Y, Henault LE, Selby JV, Singer DE. Prevalence of undiagnosed atrial fibrillation in adults: National implications for rhythm management and stroke prevention: The AnTicoagulation and Risk Factors in Atrial Fibrillation (ATRIA) Study. JAMA 2001;285:2370-2375.

2. Kim MH, Morady F, Conlon B, Kronick S, Lowell M, Bruckman D, Armstrong WF, Eagle KA. A prospective, randomized, controlled trial of an emergency departmentbased atrial fibrillation treatment strategy with lowmolecular-weight-heparin. Ann Emerg Med 2002;40:187192.

3. ACC/AHA/ESC guidelines for the management of patients with atrial fibrillation: Executive summary. $J \mathrm{Am}$ Coll Cardiol 2001;38:1-35.

4. Hirsh J, Fuster V, Ansell J, Halperin JL. American Heart Association/American College of Cardiology Foundation guide to warfarin therapy. Circulation 2003;107:16921711.

5. Connolly SJ. Preventing stroke in patients with atrial fibrillation: Current treatments and new concepts. Am Heart $J$ 2003;145:418-423.

6. Nutescu E, Racine E. Traditional versus modern anticoagulant strategies: Summary of the literature. Am J HealthSyst Pharm 2002;59 (Suppl 6):S7-14.

7. Kim MH, Decena BF, Bruckman D, Eagle KA. Use patterns of low-molecular weight heparin and the impact on length of stay in patients hospitalized for atrial fibrillation. $\mathrm{Am}$ Heart J 2003;145:665-669.

8. The Advisory Board Company (Cardiovascular Roundtable). Post-CABG atrial fibrillation: Advanced strategies for prevention and efficient treatment. Washington, D.C., 2000.

9. Harenberg J, Weuster B, Pfitzer M, Dempfle CE, Stehle G, Kubler W, Schlierf G. Prophylaxis of embolic events in patients with atrial fibrillation using low molecular weight heparin. Semin Thromb Hemostas 1993;19 (Suppl 1):116121.

10. Harenberg J, Huhle G, Piazolo L, Giese C, Heene DL. Longterm anticoagulation of outpatients with adverse events to oral anticoagulants using low-molecular weight heparin. Semin Thromb Hemostas 1997;23:167-172.

11. Roijer A, Eskilsson J, Olsson B. Transesophageal echocardiography-guided cardioversion of atrial fibrillation or flutter. Eur Heart $J$ 2000;21:837-847.

12. Philippon F, O'Hara GE, Champagne J, Charbonneau L, Villeneuve H, Blier L, Molin F, Gilbert M. DALTON Study: A randomized study comparing outpatient dalteparin administration to inpatient heparin for the initiation of anticoagulation in atrial fibrillation. J Am Coll Cardiol 2003;41 (Suppl A):85A(abstract).

13. Nixdorff U, Stellbrink C, Hofmann T, Hanrath $P$, Lehmacher W, Schmidt-Lucke A, for the ACE Investigators. Comparison of the safety and efficacy of enoxaparin with unfractionated heparin and phenprocoumon as anticoagulation in cardioversion of nonvalvular atrial fibrillation. J Am Coll Cardiol 2003:41(Suppl A):85A(abstract).

14. Albers GW, Dalen JE, Laupacis A, Manning WJ, Peterson P, Singer DE. Antithrombotic therapy in atrial fibrillation (Sixth ACCP Consensus Conference on Antithrombotic Therapy). Chest 2001;119(Suppl):194S-206S.

15. Bjerkelund CJ, Orning OM. The efficacy of anticoagulant therapy in preventing embolism related to D.C. electrical conversion of atrial fibrillation. Am J Cardiol 1969;23:208216.

16. Arnold AZ, Mick MJ, Mazurek RP, Loop FD, Trohman RG. Role of prophylactic anticoagulation for direct current cardioversion in patients with atrial fibrillation or flutter. $J$ Am Coll Cardiol 1992;19:851-855.

17. Klein AL, Grimm RA, Murray RD, Apperson-Hansen C, Asinger RW, Black IW, Davidoff R, Erbel R, Halperin JL, Orsinelli DA, Porter TR, Stoddard MF. Use of transesophageal echocardiography to guide cardioversion in patients with atrial fibrillation. $N$ Engl J Med 2001;344:1411-1420.

18. Murray RD, Deitcher SR, Shah A, Jasper SE, Bashir M, Grimm RA, Klein AL. Potential clinical efficacy and cost benefit of a transesophageal echocardiography-guided lowmolecular-weight heparin (enoxaparin) approach to antithrombotic therapy in patients undergoing immediate cardioversion from atrial fibrillation. J Am Soc Echocardiogr 2001;14:200-208.

19. Murray RD, Shah A, Jasper SE, Goodman A, Deitcher SR, Katz WE, Malouf JF, Stoddard MF, Grimm RA, Klein AL, for the ACUTE II pilot study. Transesophageal echocardiography guided enoxaparin antithrombotic strategy for cardioversion of atrial fibrillation: The ACUTE II pilot study. Am Heart $J$ 2000;139:e5.

20. Stellbrink C, Hanrath P, Nixdorff U, Hofmann T, Lehmacher W, Kuhle K, Fetsch T, Grewe R, SchmidtLucke JA. Anticoagulation in cardioversion using enoxaparin study group. Zeitschrift fur Kardiologie 2002;91:249254.

21. The Atrial Fibrillation Follow-up Investigation of Rhythm Management (AFFIRM) Investigators. A comparison of 
rate control and rhythm control in patients with atrial fibrillation. $N$ Engl J Med 2002;347:1825-1833.

22. Lip GYH, Hart RG, Conway DSG. Antithrombotic therapy for atrial fibrillation. BMJ 2002;325:1022-1025.

23. Sherman DG, Kim S, Boop B, Corley S, DiMarco J, Hart RG, Haywood LJ, Hoyte K, Kaufman ES, Kim M, Nasco E, Waldo A, for the AFFIRM Investigators. The occurrence and characteristics of stroke events in the AFFIRM study. Neurology 2003;60(Suppl 1):A326(abstract).

24. Zimetbaum PJ, Josephson ME, McDonald MJ, McClennen S, Korley V, Ho KK, Papageorgiou P, Cohen DJ. Incidence and predictors of myocardial infarction among patients with atrial fibrillation. J Am Coll Cardiol 2000;36:12231227.

25. Koenig BO, Ross MA, Jackson RE. An emergency department observation unit protocol for acute-onset atrial fibrillation is feasible. Ann Emerg Med 2002;39:374-381.
26. Mulcahy B, Coates WC, Henneman PL, Lewis RJ. New-onset atrial fibrillation: When is admission medically justified? Acad Emerg Med 1996;3:114119.

27. Weigner MJ, Thomas LR, Patel U, Schwartz JG, Burger A, Douglas PS, Silverman DI, Manning WJ. Early cardioversion of atrial fibrillation facilitated by transesophageal echocardiography: Short-term safety and impact on maintenance of sinus rhythm at one year. $A m J$ Med 2001;110:694-702.

28. Kim MH, Krishnan K, Jain S, Decena BF. Time course and frequency of subtherapeutic anticoagulation for newly prescribed warfarin anticoagulation before elective cardioversion of atrial fibrillation or flutter. Am $J$ Cardiol 2001;88:1428-1431.

29. Ginsberg JA, Crowther MA, White RH, Ortel TL. Anticoagulation therapy. Hematology 2001:339-357. 